Original paper

\title{
Education, training and registration of Medical Physics Experts across Europe
}

\author{
Ad J.J. Maas ${ }^{\mathrm{a}, *}$, Adriaan A. Lammertsma ${ }^{\mathrm{b}}$, Sam Agius ${ }^{\mathrm{c}}$, Christoph Bert ${ }^{\mathrm{d}}$, Brenda Byrne ${ }^{\mathrm{e}}$, \\ Carmel J. Caruana ${ }^{f}$, Paddy Gilligan ${ }^{\mathrm{g}}$, Efi Koutsouveli ${ }^{\mathrm{h}}$, Eric Pace ${ }^{\mathrm{i}}$, Marco Brambilla ${ }^{\mathrm{j}}$ \\ ${ }^{a}$ Past Chairperson EFOMP Professional Matters Committee, Member MREC Brabant, Tilburg, Netherlands \\ ${ }^{\mathrm{b}}$ Past Chairperson EFOMP Education \& Training Committee, Full Professor Radiology \& Nuclear Medicine, Amsterdam UMC, Netherlands \\ ${ }^{c}$ General Secretary EFOMP Professional Matters Committee, MPE Nuclear Medicine, Mater Dei Hospital, Msida, Malta \\ ${ }^{\mathrm{d}}$ Chairperson EFOMP Education \& Training Committee, Department of Radiation Oncology, Universitätsklinikum Erlangen, Friedrich-Alexander-Universität Erlangen- \\ Nürnberg, Erlangen, Germany \\ ${ }^{\mathrm{e}}$ Chairperson EFOMP Professional Matters Committee, Principal Physicist Mater Misericordiae University Hospital, Dublin 7, Ireland \\ ${ }^{\mathrm{f}}$ Member EFOMP Professional Matters and Education \& Training Committees, Full Professor of Medical Physics, Faculty of Health Sciences, University of Malta, Msida, \\ Malta \\ ${ }^{\mathrm{g}}$ President EFOMP, Chief Physicist Mater Private Hospital, Dublin, Ireland \\ ${ }^{\text {h }}$ Secretary General EFOMP, Medical Physics Expert, Department of Medical Physics, Hygeia Hospital, Athens, Greece \\ ${ }^{\mathrm{i}}$ Secretary EFOMP Education \& Training Committee, Medical Physics Expert Medical Imaging Department, Mater Dei Hospital, Msida, Malta \\ ${ }^{\mathrm{j}}$ Past President EFOMP, Director of Health Physics Department, University Hospital, Novara, Italy
}

\section{A R T I C L E I N F O}

\section{Keywords:}

European Federation of Organizations for

Medical Physics

Medical Physics Expert

Education and training

National registration scheme

Supervising committee

Professional misconduct

\begin{abstract}
A B S T R A C T
From its inception, EFOMP has pursued a policy to improve and coordinate education and training of medical physicists across all its participating European countries. Several EFOMP policy statements on education and training have been published and surveys have been held to get an overview of the actual situation. At the beginning of 2020 a new survey was distributed amongst the 36 National Member Organizations (NMOs), in which questions were based on recommendations published in the most recent policy statements. Thirty-three of the NMOs (91\%) responded, of which 22 indicated having a National Registration Scheme (NRS) for Medical Physics Experts (MPEs) in place. Another 6 indicated considering such a scheme.

Results of the questionnaire showed that there was good correspondence between education and training programmes, i.e. a division between a BSc phase, an MSc phase and a clinical phase after completion of the MSc. Differences between NRSs were primarily seen in the availability and composition of a supervising committee and in the availability of guidelines for handling professional misconduct. In addition, some differences were seen in the topics that were part of the education and training programme.

The goal of a universal (registered) MPE accepted by all European countries is still far away despite the progress being made. The new procedure for approving an existing NRS, which fulfils all EFOMP criteria is seen as an important step forward. Exchange of experience, knowledge, ideas and, above all, MPE trainees between European countries is seen as the best approach to achieve this goal.
\end{abstract}

\section{Introduction}

The European Federation of Organizations for Medical Physics (EFOMP) was formally established in May 1980. EFOMP serves as an umbrella organisation for all 36 National Member Organisations (NMOs), which together represent more than 9000 physicists and engineers working in the field of medical physics. From the outset, education and training of medical physicists was an important area of interest, as demonstrated by the first EFOMP Policy Statement (PS), published in 1984 [1]. In the following years, other policy statements on the same subject followed $[2,3,4,5,6]$. Around the year 2000, the EFOMP Board introduced a system of approval of National Registration Schemes (NRSs). Subsequently, a number of National Member Organizations (NMOs) applied and received formal approval of their NRS by

\footnotetext{
* Corresponding author.

E-mail address: adjjmaas@gmail.com (A.J.J. Maas).
} 
EFOMP. An NRS was defined as a national agreement detailing the way in which medical physicists were trained and educated, together with the availability of a formal training programme for medical physicists [2]. In addition, a form of registration was mandated including rules for investigating and dealing with professional misconduct. The rules for approval were rewritten and more extensively explained in EFOMP PS 6.1, published in 2016 [4]. At the same time, the role of the Medical Physics Expert (MPE) became clearer, especially in relation to the Council Directive EU/2013/59/EURATOM [7,8] and Radiation Protection $174[9,10]$. This necessitated a new procedure for approving an NRS, which subsequently was established by the Board in 2018. Following this new procedure, five NMOs (DGMP - Germany, NVKF Netherlands, ÖGMP - Austria, SFPM - France and IAPM - Ireland) applied for approval of their NRS according to the updated criteria. They all received approval following a thorough analysis of their NRS documentation by the Professional Matters Committee of EFOMP. This process made clear how little was known about MPE education and training procedures across Europe. An understanding of the specific implementation of education, training and registration of MPEs across the various European countries is essential to develop policies. These policies are intended to improve harmonization of the knowledge, skills and competences of MPEs, provide the possibility of free movement of MPEs between European countries and create the possibility to evaluate how EFOMP recommendations concerning education, training and registration of MPEs are implemented by the NMOs.

The involvement of professionals with a background in physics in healthcare dates back to the start of the twentieth century. Initially, support from these professionals with a technical background was needed when physicians introduced electrical therapeutic equipment [11]. The next step was the introduction of diagnostic radiographic equipment, which was followed by the use of ionizing radiation for therapeutic purposes. The medical use of ionizing radiation over the last hundred years ranges from the development of the X-ray tube to the recent introduction of particle (i.e. proton) therapy systems, which is why a majority of medical physicists are heavily involved in Radiotherapy. Other specialties are Nuclear Medicine, Diagnostic and Interventional Radiology, Hospital Physics (including non-ionizing imaging and treatment), Clinical Audiology and Clinical Neurophysiology. In the last fifty years, well defined education and training programmes for medical physicists appeared in several countries, in general initiated by the NMOs. These initiatives were pushed forward by a need to set standards for the medical physics professional in order to guarantee professional levels comparable with those of their medical colleagues [12]. Apart from EFOMP, other societies also became involved in the education and training of Medical Physicists (MPs) and MPEs in Europe. Among these societies are the European Society for Therapeutic Radiology and Oncology (ESTRO), the European Association of Nuclear Medicine (EANM), the European Society of Radiology (ESR) and the International Atomic Energy Agency (IAEA [13]). EFOMP actively supported the education and training of MPs and MPEs through its committees, which were responsible for writing policy statements and setting up dedicated entities such as the European School for Medical Physics Experts (ESMPE), the European Training and Education for Medical Physics Experts (EUTEMPE) network, the EFOMP Examination Board (EEB) and the European Board of Accreditation for Medical Physics (EBAMP). EBAMP is an independent organisation that accredits medical physics education and training events. It allocates Continuous Professional Development (CPD) credits depending on the number of hours of education and hands-on training required of participants, often followed by a formal assessment.

In order to investigate how EFOMP's policies were implemented and to assess whether these policies needed to be updated, in 2019 it was decided to carry out a survey among NMOs. This survey was designed to shed light on how MPs and MPEs are trained and registered in the European countries and what is needed to achieve a higher level of harmonization, which ultimately may lead to mutual (i.e. across
European countries) recognition of registered MPEs. This survey (in the form of a questionnaire) was carried out by EFOMP's Professional Matters and Education \& Training committees and closed in May 2020.

\section{Materials and methods}

The Presidents and delegates of all 36 NMOs of EFOMP were invited to participate in the survey. The questionnaire was designed within Google Forms in such a way that a well-informed NMO representative would be able to complete the survey within half an hour.

For convenience and clarity, the education and training programme for MPEs was divided into 3 phases and specific questions were asked with respect to each phase:

- A bachelor phase according to university standards.

- A master phase according to university standards.

- A third (clinical) phase of additional education and practical training in a clinical environment after completion of the master's degree. This phase may include postgraduate education at a university.

Every phase was assessed in terms of duration together with the amount and depth of basic and applied physics (including radiation protection). Competence training in the clinical phase was assessed using the CanMEDS system [14].

In the original questionnaire which was sent to the NMOs, these phases were defined differently. University studies for bachelor and master were defined as phase 1 and the clinical phase was divided into a pure theoretical component (phase 2) and a practical component (phase 3 ). In many educational and training schemes, phases 2 and 3 are combined and often carried out in parallel which makes a distinction superfluous.

In addition to questions regarding these 3 phases, additional questions related to examination, registration and re-registration of MPEs were included. The survey was concluded with some questions concerning procedures around professional misconduct. A complete overview of the survey is given in Fig. 1a to $1 \mathrm{c}$.

\section{Results}

Of the 36 NMOs contacted, 33 completed the form. Originally, NMOs were asked for permission to publish their individual response in combination with their name. As 6 NMOs did not agree to this, it was decided to publish all data anonymously. A summary of the results is given in table 1 . The table shows that 26 of the present $27 \mathrm{EU}$ members are represented in EFOMP and among them 25 participated in the survey. Of these, 19 countries have an existing NRS for MPEs and 3 are considering starting one. In addition, 3 non-EU member states have an NRS in place and 2 are considering starting one.

Table 2 presents more details of the various education and training programmes for MPEs. During the bachelor phase more attention was paid to fundamental and applied physics (68\%) with a shift to medical physics and radiation protection (64\%) in the master phase. Radiation protection is often seen as part of medical physics. It has to be realized that these data are coarse figures that do not take into account differences between universities within a country and the fact that some countries are made up of federal or confederal states with slightly different laws. As a result, a few NMOs had some difficulty in completing the survey. This was also the case for the third phase, which in most NRSs was used for development of the MP's clinical skills. The various responses indicated that in some cases, the title of MP was granted after completion of the master level, sometimes halfway through the practical training and not all countries recognize the title of MP but restrict themselves to the title of MPE only. This situation was further complicated by the use of alternative titles such as medical scientist, qualified medical physicist, clinical physicist, radiological physicist, or biomedical engineer. Since the title 'Medical Physics Expert' was the level 


\section{EFOMP NRS survey 2020}

EFOMP survey concerning education and training of medical physics experts

*Required

1. Email address *

2. Name of National Member Organisation (acronym) *

3. Country *

4. Does your NMO agree that your country is named in the list of responders in this survey? *

5. Does your NMO agree to have its name linked to answers given in this survey (for use in future publications and communication between NMOs)?

6. Does your country have a National Registration Scheme for the education and training of medical physics experts? *

If answered 'No' or 'This is under consideration' then skip to "Thank you for finishing the survey."

\section{PART ONE}

\section{Basic education and set-up of the National Registration Scheme}

A National Registration Scheme can be divided in several phases. This question deals with the way these phases are implemented in the National Registration Scheme of your country.

\section{Phase 1. BSc university education and training scheme}

According to RP 174 and EFOMP Policy Statement 12.1 a medical physicist should have an EQF level 6 (e.g. bachelor degree phase 1a) in physics or equivalent (e.g., appropriate engineering) and an EQF level 7 (e.g. master degree phase $2 b$ ) in medical physics or equivalent (e.g., physics or engineering Masters plus the knowledge and skills normally found in a Medical Physics masters). Please describe the educational stages of your NRS with help of a predefined text.

7. Which are the main topics which are dealt with in the bachelor phase?

Physics and mathematics (astronomy, physical chemistry and any physics-based engineering accepted as physics).

Physics, mathematics and applied physics (e.g. biomechanics, biophysics, electric engineering). Physics and medical physics.

Medical physics (including biophysics, biomedical technology, biomedical engineering and some pure medical topics, e.g. anatomy, physiology, pathology).

Medical physics and radiation protection (including biophysics, biomedical technology, biomedical engineering and some pure medical topics, e.g. anatomy, physiology, pathology).

Other:

8. What is the duration of the bachelor phase (average university years)?

\section{Phase 2. MSc university education and training scheme}

9. Which are the main topics which are dealt with in the master phase?

Physics and mathematics (astronomy, physical chemistry and any physics-based engineering accepted as physics).

Physics, mathematics and applied physics (e.g. biomechanics, biophysics, electric engineering).

Physics and medical physics.

Medical physics (including biophysics, biomedical technology, biomedical engineering and some pure medical topics, e.g. anatomy, physiology, pathology).

Medical physics and radiation protection (including biophysics, biomedical technology, biomedical engineering and some pure medical topics, e.g. anatomy, physiology, pathology).

Other:

10. What is the duration of the master phase (average university years)?

Fig. 1. Full text of the questionnaire for the EFOMP NRS survey 2020: 1a - PART ONE Phase 1 and 2; $1 \mathrm{~b}$ - PART ONE Phase 3a and 3b; 1c PART TWO Registration, reregistration and professional misconduct. 


\section{Phase 3a. Additional education in medical physics}

This concerns lectures in medical physics and related topics or a $\mathrm{PhD}$ programme in medical physics. It might be an additional education following a master degree or an introduction to medical physics in case the master curriculum did not include medical physics.

11. Which are the topics dealt with in additional education in medical physics? (more than one tick is allowed)

Medical physics

Radiation Protection

Biophysics, biomedical technology and/or biochemistry

Medical informatics including artificial intelligence

Pure medical topics (e.g. anatomy, physiology, pathology)

Medical ethics

Legislation.

12 What is the duration of the additional educational phase (average training years)?

\section{Phase 3b. Clinical training in a hospital or other healthcare institute}

In becoming a medical physicist and medical physics expert, it is essential to have clinical experience in a hospital or clinic. In some cases, this practical part of the training scheme may be combined with the education of phase 2. If so then the average training years for the clinical training may be set to 0 .

13 Which are the main topics that are covered in the clinical phase? (more than one tick is allowed).

Clinical training is not part of the registration scheme

Application of medical physics in clinical practice

Application of medical ethics (e.g. 'Good Clinical Practice')

Application of radiation protection in clinical practice

Communication (with colleagues, physicians, patients and their family, hospital administrators and industry representatives).

Working in a team

Leadership demonstrated by chairing more than one project

Demonstrating health advocacy (e.g. writing patient information or showing interest in healthcare economics)

Scholarship (e.g. being involved in a scientific research programme)

Other:

14 Are the additional educational and clinical phases intertwined (in parallel)?

15. What is the duration of the additional clinical phase for Medical Physics Expert (average training years, 0 when educational and clinical training are intertwined)?

Fig. 1. (continued). 


\section{PART TWO}

\section{Supervision of the National Registration Scheme (NRS) and Continuous Professional Development (CPD) schemes}

\section{Registration}

Direct approval by the government means that the government has reviewed the NRS and has given approval to the scheme. Indirect approval means that the government approved the installation of a body, not belonging to the government itself, and this body has approved the NRS.

16. Has the NRS formal approval by the government (Directly/Indirectly/No formal approval)?

17. Does the NRS have a supervising committee?

There is no supervising committee.

The supervising committee has formal approval by the government.

The supervising committee includes no MPEs

The supervising committee includes MPEs.

The supervising committee includes MPEs only.

The supervising committee has an EFOMP representative involved.

The supervising committee members are nominated by the NMO.

The supervising committee members are appointed by the government.

18. Which body designs the national registration scheme for MPEs?

The NMO.

The supervising committee mentioned earlier. The government.

A university or university collaboration.

Other:

19. Does the national registration scheme include a final exam?

20. When yes, which body takes the final exam?

The NMO.

The supervising committee mentioned earlier.

The government.

A university or university collaboration

21. Does the final exam include an oral component?

\section{Re-registration}

After registering an MPE there is some need to track the progression of the MPE and to ensure the MPE keeps up with the introduction of new concepts in the field. This is called a re-registration procedure.

22. Does the national registration scheme have a re-registration procedure?

23. Which is the frequency for re-registration (number of years)?

23. Which are the criteria for re-registration?

A number of points earned by continuous professional development (CPD: such as attending congresses, giving lectures, writing articles)

An amount of clinical work produced during the evaluation period. Being employed as a MPE during the evaluation period.

Other:

25. Which body is responsible for re-registration?

The NMO.

The supervising committee mentioned earlier. The government.

A university or university collaboration.

Other.

\section{Professional misconduct}

26. Does the NMO have a regulation that describes professional misconduct in line with EFOMP Policy Statement 11?

27. Which body usually handles professional misconduct (e.g. disciplinary actions)?

The NMO.

The supervising committee mentioned earlier.

The government.

A university or university collaboration.

Other.

Fig. 1. (continued). 
Table 1

List of European countries represented in EFOMP. The ' $\mathrm{C}$ ' refers to considering to set up an NRS in the near future.

\begin{tabular}{|c|c|c|c|}
\hline Country & EU member & Responded & NRS present \\
\hline Albania & & $\mathrm{Y}$ & $\mathrm{N}$ \\
\hline Austria & $\mathrm{Y}$ & $\mathrm{Y}$ & $\mathrm{Y}$ \\
\hline Belgium & $\mathrm{Y}$ & $\mathrm{Y}$ & $\mathrm{C}$ \\
\hline \multicolumn{4}{|l|}{ Bosnia-Herzegovina } \\
\hline Bulgaria & $\mathrm{Y}$ & $\mathrm{Y}$ & $\mathrm{Y}$ \\
\hline Croatia & $\mathrm{Y}$ & $\mathrm{Y}$ & $\mathrm{N}$ \\
\hline Cyprus & $\mathrm{Y}$ & $\mathrm{Y}$ & $\mathrm{N}$ \\
\hline Czech Republic & $\mathrm{Y}$ & $\mathrm{Y}$ & $\mathrm{Y}$ \\
\hline Denmark & $\mathrm{Y}$ & $\mathrm{Y}$ & $\mathrm{Y}$ \\
\hline Estonia & $\mathrm{Y}$ & $\mathrm{Y}$ & $\mathrm{Y}$ \\
\hline Finland & $\mathrm{Y}$ & $\mathrm{Y}$ & $\mathrm{Y}$ \\
\hline France & $\mathrm{Y}$ & $\mathrm{Y}$ & $\mathrm{Y}$ \\
\hline Germany & $\mathrm{Y}$ & $\mathrm{Y}$ & $\mathrm{Y}$ \\
\hline Greece & $\mathrm{Y}$ & $\mathrm{Y}$ & $\mathrm{Y}$ \\
\hline Hungary & $\mathrm{Y}$ & $\mathrm{Y}$ & $\mathrm{Y}$ \\
\hline Ireland & $\mathrm{Y}$ & $\mathrm{Y}$ & $\mathrm{Y}$ \\
\hline Italy & $\mathrm{Y}$ & $\mathrm{Y}$ & $\mathrm{Y}$ \\
\hline Latvia & $\mathrm{Y}$ & $\mathrm{Y}$ & $\mathrm{N}$ \\
\hline Lithuania & $\mathrm{Y}$ & $\mathrm{Y}$ & $\mathrm{Y}$ \\
\hline \multicolumn{4}{|l|}{ Rep. North Macedonia } \\
\hline Malta & $\mathrm{Y}$ & $\mathrm{Y}$ & $\mathrm{Y}$ \\
\hline Moldova & & $\mathrm{Y}$ & $\mathrm{N}$ \\
\hline Netherlands & $\mathrm{Y}$ & $\mathrm{Y}$ & $\mathrm{Y}$ \\
\hline Norway & & $\mathrm{Y}$ & $\mathrm{Y}$ \\
\hline Poland & $\mathrm{Y}$ & $\mathrm{Y}$ & $\mathrm{Y}$ \\
\hline Portugal & $\mathrm{Y}$ & $\mathrm{Y}$ & $\mathrm{C}$ \\
\hline Romania & $\mathrm{Y}$ & $\mathrm{Y}$ & $\mathrm{Y}$ \\
\hline Russia & & $\mathrm{Y}$ & $\mathrm{N}$ \\
\hline Serbia & & $\mathrm{Y}$ & $\mathrm{C}$ \\
\hline Slovakia & $\mathrm{Y}$ & $\mathrm{Y}$ & $\mathrm{C}$ \\
\hline Slovenia & $\mathrm{Y}$ & & \\
\hline Spain & $\mathrm{Y}$ & $\mathrm{Y}$ & $\mathrm{Y}$ \\
\hline Sweden & $\mathrm{Y}$ & $\mathrm{Y}$ & $\mathrm{Y}$ \\
\hline Switzerland & & $\mathrm{Y}$ & $\mathrm{Y}$ \\
\hline United Kingdom & & $\mathrm{Y}$ & $\mathrm{Y}$ \\
\hline Ukraine & & $\mathrm{Y}$ & $\mathrm{C}$ \\
\hline Number of countries & 26 & 33 & $22 \mathrm{Y}, 5 \mathrm{C}$ \\
\hline
\end{tabular}

Table 2

Summary of the results of the NRS survey for the three phases of education and training of MPEs. The figures are from 22 countries reporting to have an NRS running.

\begin{tabular}{|c|c|c|c|c|c|}
\hline & \multirow{2}{*}{$\frac{\text { Phase } 1}{\text { BSc }}$} & \multirow{2}{*}{$\frac{\text { Phase } 2}{\text { MSc }}$} & \multicolumn{2}{|l|}{ Phase 3} & \multirow[t]{2}{*}{ Total } \\
\hline & & & Post grad & late & \\
\hline Duration median (years) & 3 & 2 & 4 & & 9 \\
\hline Duration min-max (years) & 3 to 4 & 1 to 2 & $\begin{array}{l}2 \text { to } 6.5 \\
\text { Theory }\end{array}$ & Clinic & 7 to 11.5 \\
\hline Not defined & 1 & 1 & & & \\
\hline Physics and mathematics & 8 & 2 & & & \\
\hline Applied physics & 7 & 4 & & & \\
\hline Physics and medical physics & 4 & 5 & & & \\
\hline Medical physics & 1 & 2 & 20 & 22 & \\
\hline Radiation protection & 1 & 7 & 20 & 22 & \\
\hline Biophysics & & & 8 & & \\
\hline Medical informatics & & & 11 & & \\
\hline Medicine & & & 17 & & \\
\hline Medical ethics & & & 11 & 16 & \\
\hline Legislation & & & 17 & & \\
\hline Communication & & & & 17 & \\
\hline Collaboration & & & & 19 & \\
\hline Leadership & & & & 10 & \\
\hline Health advocacy & & & & 7 & \\
\hline Science and Research & & & & 8 & \\
\hline Total & 22 & 21 & & & \\
\hline
\end{tabular}

Table 3

Summary of the results of the NRS survey for supervision of education and training and continuous professional development. The figures are from 22 countries reporting to have an NRS running. (Gov = Government).

\begin{tabular}{|c|c|c|c|c|c|}
\hline \multirow{3}{*}{$\begin{array}{l}\text { Supervising } \\
\text { committee present } \\
\text { Supervising } \\
\text { committee } \\
\text { composition }\end{array}$} & \multicolumn{5}{|l|}{ Total } \\
\hline & 21 & 8 approv & d by Gc & ernment & \\
\hline & & $\begin{array}{l}7 \text { only } \\
\text { MPs }\end{array}$ & $\begin{array}{l}8 \\
\text { MPs }\end{array}$ & 1 no MPs & $\begin{array}{l}5 \text { not } \\
\text { specified }\end{array}$ \\
\hline $\begin{array}{l}\text { Supervising } \\
\text { committee } \\
\text { dependence }\end{array}$ & & $8 \mathrm{NMO}$ & $\begin{array}{l}7 \\
\text { Gov }\end{array}$ & $\begin{array}{l}2 \\
\text { independent }\end{array}$ & $\begin{array}{l}4 \text { not } \\
\text { specified }\end{array}$ \\
\hline
\end{tabular}

addressed by the European directive, it was decided to focus on the title of MPE for this survey. Theoretical topics during the third phase are medical physics and radiation protection (91\%), medicine and legislation (77\%) and medical informatics together with medical ethics (50\%). In the light of competences as defined by the CanMEDS system, attention was paid to collaboration (86\%), communication (77\%), medical ethics (73\%), leadership (45\%), science and research (36\%) and health advocacy (32\%). The median duration for the three phases were 3 (3 to 4 ) years for bachelor, 2 ( 1 to 2 ) years for master and 4 ( 2 to 6.5 ) years for the clinical phase, respectively, which makes an median of 9 (7 to 11.5) years for the full NRS training programme.

Table 3 shows that 21 out of the 22 NRSs are monitored by a supervising committee, of which 8 have governmental approval. Seven supervising committees are controlled by the government, eight by the NMO and two are reported to be an independent organization. Seven supervising committees are composed exclusively by medical physicists (MPs and MPEs). Eight supervising committees have a mixed composition, including medical physicists, and one reported having no medical physicist in its committee. Five NMOs reported to have an EFOMP representative, possibly an EFOMP delegate or officer, in the supervising committee. Five NMOs did not specify the composition of their supervising committee.

Several parties may be involved in developing the NRS curriculum (table 4). These parties are the NMO (8), the supervising committee (12), the government (10) and one or more universities (4). As many as 18 NRSs have some form of formal approval by the government. Ten have direct approval by the government and eight are indirectly approved.

Registration as an MPE follows after completing the third phase of the education and training programme (table 4). 14 education \& training programmes close with a final exam. Final exams involve the supervisory committee (7), the NMO (3), the government (2) or a university (3). Ten out of the fourteen final exams have an oral component. Re-registration of MPEs is reported to be part of 16 NRSs of which one was voluntary. The average interval between successive re-registrations is 4.5 years with a range from 2 to 5 years. Criteria for re-registration are acquired accreditation points (16), employment (8) and ongoing performance of clinical work (5). Bodies responsible for evaluation of reregistration criteria may be the supervising committee (9), the NMO (4) or the government (3), and in one case it was not defined. About half of the NRSs have a procedure available for handling professional misconduct. Bodies involved in this procedure are the supervising committee (5), the NMO (5) or the government (5), and in 6 cases it was not specified.

\section{Discussion}

Not surprisingly, the survey demonstrated that NMOs in different European countries follow different paths to educate and train MPEs. 
Table 4

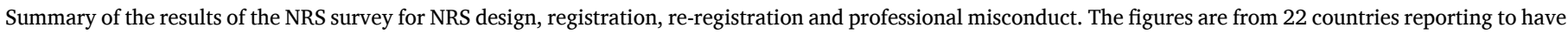
an NRS running. (SC = Supervising Committee; Gov = Government, Uni = university, resp. $=$ responsible).

\begin{tabular}{|c|c|c|c|c|c|c|c|}
\hline \multirow{2}{*}{\multicolumn{2}{|c|}{ NRS design (involvement) }} & \multicolumn{6}{|l|}{ Total } \\
\hline & & $22 *)$ & $12 \mathrm{SC}$ & $8 \mathrm{NMO}$ & 10 Gov & 4 Uni & \\
\hline \multicolumn{2}{|c|}{ NRS approved by Government } & 18 & 10 direct & & 8 indirect & & \\
\hline \multicolumn{2}{|c|}{ NRS final exam (involvement) } & $14 *)$ & $7 \mathrm{SC}$ & $3 \mathrm{NMO}$ & 2 Gov & 3 Uni & \\
\hline \multicolumn{2}{|c|}{ NRS oral exam } & 10 & & & & & \\
\hline \multirow[t]{3}{*}{ NRS re-registration } & Interval & $15 *)$ & \multicolumn{2}{|c|}{ Average 4.5 years } & \multicolumn{3}{|c|}{ Range $2-5$ years } \\
\hline & Criteria & & \multicolumn{2}{|c|}{16 Credit points } & \multicolumn{2}{|c|}{5 clinical work } & 8 employment \\
\hline & Resp. body & & 9 SC & $4 \mathrm{NMO}$ & 3 Gov & 0 Uni & 1 not defined \\
\hline \multicolumn{2}{|c|}{ Professional misconduct (resp. body) } & $12 *)$ & $5 \mathrm{SC}$ & 5 NMO & 5 Gov & 0 Uni & 6 not defined \\
\hline
\end{tabular}

*) A combination of involved parties (e.g. NMO and Government) was reported by some NMOs.

However, most NMOs conform to a few basic rules which are essential to guarantee the quality of the MPE [13]. These rules are:

- A good foundation in basic Physics and Mathematics, especially during the Bachelor phase.

- The Master phase is used to strengthen fundamental Physics knowledge and to introduce subjects that are relevant for Medical Physicists, like Biophysics, Radiation Protection, Medical Physics, Biomedical Engineering and Teaching.

- The clinical phase is used to introduce forthcoming medical physicists to clinical practice and for collaboration with both medical doctors and other health professionals. In addition, this phase is used to specialise in one of the working fields of medical physics. Depending on the length of this phase, there is room for maturation of the professional.

The quality of the basic Physics and Mathematics education may be defined by the number of ECTS credits (European Credit Transfer and Accumulation System [15]) attributed to fundamental Physics and Mathematics (e.g. mechanics, electromagnetics, quantum mechanics, nuclear physics, thermodynamics, optics, algebra and calculus). Within the field, there is growing consensus that 100-200 ECTS credits should be devoted to fundamental physics and mathematics to ensure strong scientific foundations and analytical thinking skills [16]. These ECTS credits may be divided between Bachelor and Master phases. It may be attractive to include other subjects, such as Biophysics, Medical Physics, Radiation Protection and Medical Technology, in the Bachelor phase, especially if the Bachelor phase takes more than 2 years.

In most universities there is more room for personal preferences of the student during the Master phase and there is also time to perform research. In general, a shift is noticed from pure physics during the Bachelor phase to physics as applied in medicine and biology, and in most cases radiation protection is included (table 2). Referring to the Council Directive EU/2013/59/EURATOM [7] and Radiation Protection 174 [10], it is mandatory to pay good attention to this topic in order to grant the title of MP or MPE at the end of the education and training programme. A Master degree is the best guarantee for a level 7 learning outcome according to the European Qualifications Framework [17].

Most differences between countries can be seen in the postgraduate education and learning programme. This is due to available learning environments, which are preferably hospitals with experience in teaching in a clinical and scientific environment, e.g. university hospitals. Next, differentiation is caused by sub-specialisations within Medical Physics itself. Most countries have education and training programmes for Radiotherapy, Nuclear Medicine and Diagnostic and Interventional Radiology. Education and training programmes for Hospital Physics (where, in addition to Medical Imaging, attention is given to Operating Room and Intensive Care facilities), Clinical Neurology, Clinical Audiology, Hospital Laboratory and more are only found in a few countries. There is no immediate need to change this situation, as long as the basic training is guaranteed by both BSc and MSc programmes and sufficient time is spent on the development of personal skills in a clinical environment. With regards to the latter skills, however, there are also many differences between countries, as shown in table 2. This especially concerns leadership, health advocacy and science and research. The CanMEDS system, developed by the Royal College of Physicians and Surgeons of Canada in order to define the most important skills for healthcare professionals [14], is not well known within Medical Physics societies and this should change.

Another difference between countries, which became visible when analysing the responses of the NMOs, was the use of titles for the medical physics professional. Not all NMOs use the title of Medical Physicist (MP) and besides Medical Physics Expert (MPE), other titles like Qualified Medical Physicist, Specialised Medical Physicist and Clinical Physicist are used. In some countries, MP is used as title for an intermediate stage towards the title of MPE. This can be the case immediately after entering an MPE education and training programme or a little bit later. There are no objections against this practice, as the professional is already acting as a medical physicist in the clinic. The use of MPE should be limited to professionals who have completed the full education and training programme for MPEs. Other professional titles are for local use and should have their proper translation into MP and MPE for international use.

The presence of a supervising committee to guard the quality of the education and training programme was also investigated in the survey and 21 out of the 22 NRSs indicated to have such a body. From these data it may be deduced that the presence of a supervising committee should be mandatory. As shown in table 4, differences occurred with respect to Government approval (8), the presence or absence of MPEs in the committee, and the dependency of the committee on NMO (8) and/ or Government (7). Two NMOs reported that the supervising committee in their countries were fully independent. No conclusions may be drawn from these data concerning composition and authority of the supervising committee. Answers to these questions may be given by the tasks assigned to the supervising committee. In reference to the trias politica the supervising committee may define the curricula for the MPE subspecialties and guarantee the quality of education and training programme as implemented by the training institutes, provided that these tasks are performed by different bodies of the supervising committee. Another solution is to assign the task of defining the curricula to the $\mathrm{NMO}$, one or more universities or the Government. Most Governmental organisations, however, lack the knowledge to write a suitable curriculum for MPEs. Nevertheless, approval of the NRS by the Government, which is the case in 18 out of 22 countries with an NRS (10 direct approval and 8 indirect approval), is the best sign of formal recognition of the MPE.

Fifteen out of 22 countries with an NRS reported to have a system for MPE registration and re-registration in place (table 4). A reliable system for MPE registration and re-registration is essential to guarantee the quality of the professional and it motivates him or her to take part in CPD. This is why a system for registration and re-registration of MPEs is one of the 8 EFOMP criteria for NRS approval [4].

Separate from a system of registration and re-registration, a system to monitor professional conduct of registered MPEs is necessary to 
control the quality of the professionals, similar to that of physicians. However, only about half of the NMOs with an NRS reported that they have a procedure for handling professional misconduct.

\section{Conclusions}

In conclusion, it is clear that there is still a long way to go in order to reach the goal of a universal MPE accepted by all European countries. Agreement concerning the way MPEs are trained and registered improves the overall quality of the profession and facilitates mobility of professionals between European countries. The steps to be taken can be summarised as follows:

1. All European countries should have an approved NRS in place. This means that the remaining 14 of the 36 NMOs should implement an NRS or collaborate closely with another NMO that has an active NRS in place. Furthermore, as only 5 out of 22 implemented NRSs are approved by EFOMP, more NMOs should apply for NRS approval by EFOMP. This guarantees the presence of a system for MPE registration and re-registration and a system how to handle professional misconduct.

2. NRS approval by EFOMP may be considered as a first step, but the criteria defined by EFOMP [4] need extension concerning the contents of the curricula. Some kind of international surveillance of national education and training programmes for MPEs will also support the acceptance of the registered MPE throughout Europe. A final assessment coordinated by a body independent from EFOMP may be a starting point. This evaluation should not be focussed on testing the knowledge of candidates, but evaluate the individual education and training programme together with the candidate's skills and competences.

3. Differences between national education and training programmes must be accepted and should not be a serious obstacle for mutual recognition of MPE registration. Therefore, it is important to develop generic requirements for education and training programmes, which could be a first step to a uniform training and registration scheme across Europe.

4. Mutual understanding between NMOs may increase by exchange of MPE trainees between countries, which may also enhance the development of individual emerging MPEs and the medical physics profession in general.

\section{References}

[1] Kaul, A., A. Benini, D.H. Bekkering, J. Chavaudra and R. Ellis. EFOMP Policy Statement Nr. 1. Medical Physics Education and Training: The present European
Level and Recommendations for its Future Development 1984, https://www. efomp.org/uploads/policy_statement_nr_1.pdf [accessed 2 February 2021].

[2] EFOMP Policy Statement Nr. 6: Recommended guidelines of National Registration Schemes for Medical Physicists, Phys Med 1995;XI:157-159.

[3] Sheahan NF, Sherriff S, Lamm IL. EFOMP Policy Statement Nr. 8, Continuing Professional Development for the Medical Physicist, Phys Med 1998;XIV:81-83.

[4] Christofides S, Isidoro J, Pesznyak C, Bumbure L, Cremers F, Schmidt WFO. The European Federation of Organisations for Medical Physics Policy Statement No. 6.1: Recommended Guidelines on National Registration Schemes for Medical Physicists. Phys Med. 2016;32(1):1-6.

[5] Christofides S, Isidoro J, Pesznyak C, Cremers F, Figueira R, van Swol C, et al. The European Federation of Organisations for Medical Physics Policy Statement No. 10.1: Recommended Guidelines on National Schemes for Continuing Professional Development of Medical Physicists. Phys Med 2016;32(1):7-11.

[6] Caruana CJ, Christofides S, Hartmann GH. European Federation of Organisations for Medical Physics (EFOMP) policy statement 12.1: Recommendations on medical physics education and training in Europe 2014. Phys Med 2014;30(6):598-603.

[7] EC. COUNCIL DIRECTIVE 2013/59/EURATOM of 5 December 2013 laying down basic safety standards for protection against the dangers arising from exposure to ionising radiation, and repealing Directives 89/618/Euratom, 90/641/Euratom, 96/29/Euratom, 97/43/Euratom and 2003/122/Euratom.

[8] Caruana CJ, Tsapaki V, Damilakis J, Brambilla M, Martín GM, Dimov A, et al. EFOMP policy statement 16: The role and competences of medical physicists and medical physics experts under 2013/59/EURATOM. Phys Med 2018;48:162-8.

[9] Guibelalde E, Christofides S, Caruana CJ, Evans S, van der Putten W. EC Radiation Protection No 174, European Guidelines on Medical Physics Expert, European Union, 2014, ISBN 978-92-79-35786-2. https://ec.europa.eu/energy/sites/ener/ files/documents/174.pdf [accessed 17 March 2021].

[10] EFOMP Policy Statement No 9 Radiation Protection of the Patient in Europe: The Training of the Medical Physics Expert in Radiation Physics or Radiation Technology, Phys Med. 1999;XV:149-153.

[11] Simon, K.J. De wetenschappelijke ontwikkelingen in de radiologie en radiotherapie binnen de geneeskunde in Nederland 1896-1922, Thesis Rijksuniversiteit Groningen, Erasmus Publishing (2015), Summary and conclusions 317-333. ISBN 978-90-367-7621-9, https://www.rug.nl/research/portal/files/15832649/ Complete_dissertation.pdf [accessed 2 February 2021].

[12] Evans S, Christofides S, Brambilla M. The European Federation of Organisations for Medical Physics. Policy Statement No. 7.1: The roles, responsibilities and status of the medical physicist including the criteria for the staffing levels in a Medical Physics Department approved by EFOMP Council on 5th February 2016. Phys Med 2016;32:533-40

[13] IAEA Training Course Series No. 71. Guidelines for the Certification of Clinically Qualified Medical Physicists, IAEA-TCS-71, ISSN 1018-5518 (2021), https://wwwpub.iaea.org/MTCD/Publications/PDF/TCS-71web.pdf?fbclid=IwAR3EVj1_ tN665wUSrUwoHYfA-ufU-mp_8awM64YViV1pyuhoFeHj1M88jtQ [accessed 12 February 2021].

[14] The Royal College of Physicians and Surgeons of Canada. CanMEDS Interactive, http://canmeds.royalcollege.ca [accessed 2 February 2021].

[15] European Commission, Directorate-General for Education, Youth, Sport and Culture. ECTS users' guide. ISBN 978-92-79-09728-7 (2009), https://op.europa eu/en/publication-detail/-/publication/9ac30b32-f6af-486e-ba4b-891459942bfd/ language-en/format-PDF/source-search [accessed 13 March 2021].

[16] Garibaldi C, Essers M, Heijmen B, Koutsouveli E, Maas AJJ, Clark CH, et al. Towards an updated ESTRO-EFOMP core curriculum for education and training of Medical Physics Experts in Radiotherapy - Assessment of current training practice in Europe. Phys Med Forthcoming 2021.

[17] European Commission, Education \& Culture. The European Qualifications Framework for Lifelong Learning (EQF). ISBN 978-92-79-08474-4 (2008), http:// ecompetences.eu/wp-content/uploads/2013/11/EQF_broch_2008_en.pdf [accessed 2 February 2021]. 